\title{
Germinação in vitro de Passiflora gibertii N. E. Brown com escarificação mecânica e ácido giberélico
}

\section{In vitro germination of Passiflora gibertii $\mathbf{N}$. E. Brown with mechanical scarification and gibberellic acid}

\author{
Milene Alves de Figueiredo Carvalho ${ }^{1 *}$; Renato Paiva ${ }^{2}$; Daiane Peixoto Vargas ${ }^{3}$; \\ Jorge Marcelo Padovani Porto ${ }^{4}$; Raírys Cravo Herrera ${ }^{5}$; Vanessa Cristina Stein ${ }^{6}$
}

\begin{abstract}
Resumo
No presente trabalho, objetivou-se analisar alguns aspectos da germinação in vitro de sementes de maracujazeiro Passiflora gibertii N. E. Brown, quanto ao tipo de escarificação, o efeito do uso do regulador de crescimento $\mathrm{GA}_{3}$ e utilização de sementes frescas ou secas. Para tanto, sementes de frutos maduros foram lavadas em água corrente e, posteriormente, colocadas para secar por quatro dias (sementes secas). Após esse período, novas sementes foram isoladas dos frutos e lavadas em água corrente para serem utilizadas imediatamente (sementes frescas). Foram avaliados diferentes tipos de escarificação (retirada da extremidade da semente com o auxílio de pinça e bisturi, retirada da extremidade da semente com lixa, manualmente, e o tratamento controle - ausência de escarificação). Após escarificação, as sementes foram inoculadas em meio de cultura MS, contendo metade da concentração dos sais, suplementado com diferentes concentrações de $\mathrm{GA}_{3}(0 ; 28,87 ; 57,74 ; 86,61$ e $115,47 \mu \mathrm{M})$ e mantidas em sala de crescimento sob condições controladas. O delineamento estastístico utilizado foi o inteiramente casualizado, em esquema fatorial triplo $3 \times 2 \times 5$ (procedimento de escarificação, semente fresca ou seca e concentração de $\mathrm{GA}_{3}$ ), com quatro repetições por tratamento, cada uma composta por cinco tubos de ensaio, cada tubo contendo uma semente. A avaliação foi realizada em intervalos de dois dias durante 45 dias, sendo observados a porcentagem de sementes germinadas e o índice de velocidade de germinação (IVG). Maiores médias para as variáveis analisadas foram obtidas com a utilização de escarificação das sementes utilizando-se pinça e bisturi. Maiores médias para percentagem de germinação foram observadas para sementes secas quando se utiliza escarificação da extremidade da semente. A adição do regulador de crescimento $\mathrm{GA}_{3}$ ao meio de cultura não obteve efeito sobre as variáveis analisadas. Palavras-chave: $\mathrm{GA}_{3}$, cultura de tecidos, sementes frescas e secas, maracujazeiro nativo
\end{abstract}

\begin{abstract}
The objective of this work was to study the in vitro germination of Passiflora gibertii N. E. Brown seeds, regarding the scarification type, the effect of using $\mathrm{GA}_{3}$ growth regulator and the use of fresh or dry seeds. Ripe fruit seeds were washed in water and dried for four days (dry seeds). After this period, new seeds were isolated from fruits and washed in water (fresh seeds). Different scarification methods were
\end{abstract}

${ }^{1}$ Pesquisadora, Embrapa Arroz e Feijão, Santo Antônio de Goiás, GO. E-mail: milene@cnpaf.embrapa.br

${ }^{2}$ Prof. Associado, Universidade Federal de Lavras, Setor de Fisiologia Vegetal, Dept ${ }^{\circ}$ de Biologia, Campus Universitário, Lavras, MG. E-mail: renpaiva@dbi.ufla.br

${ }^{3}$ Pós-doutoranda, Embrapa Clima Temperado, Pelotas, RS. E-mail: dvbio@hotmail.com

${ }^{4}$ Doutorando, Universidade Federal de Lavras, Setor de Fisiologia Vegetal, Dept ${ }^{0}$ de Biologia, Campus Universitário, Lavras, MG. E-mail: marcelo_pado@yahoo.com.br

${ }^{5}$ Prof Adjunta, Universidade Federal do Pará, Campus Universitário de Altamira, Altamira, PA. E-mail: rairys@gmail.com

${ }^{6}$ Prof ${ }^{a}$ Adjunta, Universidade Federal de Goiás, Campus Universitário, Jataí, GO. E-mail: vanessa.stein@hotmail.com

* Autor para correspondência 
tested (removing the tip seed by using forceps and scalpel or with sandpaper and the control treatment with no scarification). After scarification, seeds were inoculated in MS culture medium, containing half of its salt concentration supplemented with different concentrations of $\mathrm{GA}_{3}(0,28.87,57.74,86.61$ and $115.47 \mu \mathrm{M})$ and were kept in a growth room under controlled conditions. The experimental design used was completely randomized in a triple factorial scheme $3 \times 2 \times 5$ (scarification type, fresh or dry seeds and $\mathrm{GA}_{3}$ concentration) with four replications per treatment, each one consisting of five test tubes and each tube containing one seed. The evaluation was carried out in intervals of two days for 45 days. The percentage of germinated seeds and the germination speed index (GSI) were observed. Highest averages for the variables analyzed were obtained with the seed tip scarification by using forceps and scalpel. The highest percentage of germination was obtained for dry seeds with the seed tip scarification. The $\mathrm{GA}_{3}$ growth regulator addition to the culture medium had no effect on the analyzed variables.

Key words: $\mathrm{GA}_{3}$, tissue culture, fresh and dry seeds, native passion fruit

O estabelecimento dos bancos ativos de germoplasma (BAGs) in vitro tem sido bem sucedido para algumas espécies de maracujazeiro, especialmente para aquelas que exigem produção de matrizes livres de vírus, com a vantagem da economia de espaço e simplificação nos procedimentos de intercâmbio e quarentena de plantas. A falta de protocolos de regeneração e conservação in vitro não tem permitido, ainda, o uso extensivo deste processo de manejo de germoplasma (LIMA et al., 2008). O cultivo in vitro tem sido dificultado devido a necessidade de repetidos subcultivos, a exigência de infra-estrutura e de mão-de-obra especializadas e a freqüente contaminação fitossanitária.

A espécie Passiflora gibertii N. E. Brown possui potencial de utilização como porta enxerto e também no melhoramento genético, pela sua resistência à morte prematura, à cladosporiose, à bacteriose e à antracnose (JUNQUEIRA et al., 2005). Plântulas germinadas in vitro podem constituir ótima fonte de explantes para estudos de morfogênese. Todavia, sementes do maracujazeiro apresentam dormência sob condições in vitro, ocasionando taxas de germinação baixas e desuniformes (JUNGHANS; VIANA; JUNGHANS, 2006).

Pesquisas recentes mencionam a germinação in vivo de Passiflora gibertii sob viveiro coberto com sombrite proporcionando $50 \%$ de sombreamento, em tubetes com casca de Pinus e carvão ativado, proporcionando taxa de germinação de $47 \%$, que é considerada baixa (RONCATTO et al., 2006).

A germinação pode ser promovida pela aplicação de reguladores de crescimento, tais como auxinas, citocininas, giberelinas (GAs), etileno e outros. Desses reguladores, as giberelinas estão diretamente relacionadas à germinação de muitas sementes, uma vez que sua aplicação exógena promove a expressão dos genes que controlam a síntese das enzimas envolvidas na degradação de paredes celulares do endosperma, induzindo o crescimento do embrião e estimulando o processo germinativo. Além disso, as giberelinas contrabalanceiam a inibição imposta pelo ácido abscísico, provocando um aumento endógeno de GAs, que torna evidente sua participação na superação da dormência das sementes (CARDOSO, 2004). O tipo de GA mais utilizado in vitro é o ácido giberélico $\left(\mathrm{GA}_{3}\right)$ (BRAUN et al., 2010; SANTOS et al., 2010).

Para a cultura do maracujazeiro, não existem informações suficientes sobre a germinação in vitro. Isto demonstra a importância deste tipo de estudo para contribuir no sucesso da fase de estabelecimento in vitro que precede a micropropagação por meio de explantes derivados de sementes. Desse modo, o objetivo deste trabalho foi estudar aspectos da germinação in vitro de sementes de maracujazeiro Passiflora gibertii N. E. Brown quanto ao tipo de escarificação, uso se sementes frescas ou secas e utilização do regulador de crescimento, $\mathrm{GA}_{3}$.

Como material vegetal, foram utilizados frutos maduros de maracujazeiro Passiflora gibertii N. E. Brown - acesso CPAC MJ-22-01 da coleção de germoplasma da Embrapa Cerrados (CPAC), Planaltina, DF, coletados em julho de 2006. 
Após a abertura dos frutos por corte longitudinal com auxílio de pinça e bisturi, as sementes foram lavadas em água corrente, com peneira, para a retirada do arilo. Posteriormente, foram colocadas para secar à sombra por quatro dias (sementes secas). Após quatro dias, novos frutos foram abertos por corte longitudinal, isolando-se as sementes, que foram tratadas de maneira idêntica à descrita anteriormente, exceto no que se refere à secagem, as quais denominaram-se sementes frescas

Os dois grupos de sementes foram transferidos para a câmara de fluxo laminar e com auxílio de peneira, foram imersas em etanol $70 \%(\mathrm{v} / \mathrm{v})$ por 60 segundos e em solução de hipoclorito de sódio (NaOCl) com $1 \%$ de cloro ativo, acrescido de Tween $20^{\circledR}$ (uma gota por $100 \mathrm{~mL}$ de hipoclorito) por 20 minutos e lavadas três vezes em água destilada e autoclavada.

Foram testados diferentes procedimentos de escarificação (retirada da extremidade da semente com o auxílio de pinça e bisturi, retirada da extremidade da semente com lixa, manualmente, e o tratamento controle - ausência de escarificação) com a finalidade de superar a dormência das sementes.

Sementes cujas extremidades foram escarificadas com lixa, foram previamente imersas em etanol $70 \%$ (v/v), por 60 segundos e em solução de hipoclorito de sódio $(\mathrm{NaOCl})$ com $1 \%$ de cloro ativo, acrescido de Tween $20^{\circledR}$ (uma gota por $100 \mathrm{~mL}$ de hipoclorito), por 10 minutos e lavadas três vezes em água destilada e autoclavada. Após a escarificação manual, foram imersas novamente em hipoclorito, com $1 \%$ de cloro ativo, acrescido de Tween $20 \AA$ (uma gota por $100 \mathrm{~mL}$ de hipoclorito), por 10 minutos e lavadas três vezes em água destilada e autoclavada. Após a escarificação, as sementes foram inoculadas em tubos de ensaio contendo $15 \mathrm{~mL}$ de meio de cultura MS (MURASHIGE; SKOOG, 1962) contendo metade da concentração de seus sais, suplementado com diferentes concentrações de $\mathrm{GA}_{3}(0 ; 28,87 ; 57,74$; $86,61$ e $115,47 \mu \mathrm{M})$, sacarose $(3 \%)$ e solidificado com ágar $(0,5 \%)$. O pH do meio foi ajustado para
$5,8 \pm 1$ antes da autoclavagem, a $120^{\circ} \mathrm{C}$, durante 20 minutos. Após inoculadas, as sementes foram mantidas em sala de crescimento sob irradiância de fótons de $36 \mu \mathrm{mol} \mathrm{m}{ }^{-2} \mathrm{~s}^{-1}$, temperatura de $25 \pm 2^{\circ} \mathrm{C}$ e fotoperíodo de 16 horas.

A avaliação foi realizada em intervalos de dois dias, durante 45 dias, sendo observados a percentagem de sementes germinadas e o índice de velocidade de germinação (IVG), em cada tratamento. Foi considerada germinada a semente que apresentava a radícula protundida.

O delineamento estastístico utilizado foi o inteiramente casualizado, em esquema fatorial triplo $3 \times 2 \times 5$ (tipo de escarificação, sementes frescas ou secas e concentração de $\mathrm{GA}_{3}$ ), com quatro repetições por tratamento, cada uma composta por cinco tubos de ensaio, cada tubo contendo uma semente. Os resultados foram submetidos à análise de variância, utilizando-se o software estatístico Sisvar ${ }^{\circledR}$, sendo as médias dos tratamentos comparados pelo teste de Tukey a 5\% de significância.

Observou-se interação significativa entre 0 tipo de semente (fresca ou seca) utilizada e o procedimento de escarificação, não se verificando efeito significativo das concentrações de $\mathrm{GA}_{3}$.

Com relação à percentagem de germinação, a maior média foi obtida com a escarificação da extremidade das sementes secas com pinça e bisturi (91\%) (Figura 1). Observou-se que, para as sementes frescas, não houve diferença estatística entre escarificação da extremidade da semente com lixa $(74 \%)$ e com a utilização de pinça e bisturi $(86 \%)$. Porém, esta última, apresentando maior percentagem, para sementes secas, pode ser indicada como a melhor forma de escarificação para a superação de dormência das sementes de Passiflora gibertii in vitro. A ausência de escarificação proporcionou as menores taxas de germinação, tendo, para as sementes secas, havido ausência de germinação e para sementes frescas apenas 10\% (Figura 1). Pode-se inferir que a espécie Passiflora gibertii possui dormência extra-embrionária, superada facilmente por ação mecânica. 
Figura 1. Porcentagem de germinação in vitro de sementes frescas e secas de Passiflora gibertii submetidas a escarificação para superação de dormência, após 45 dias de cultivo.

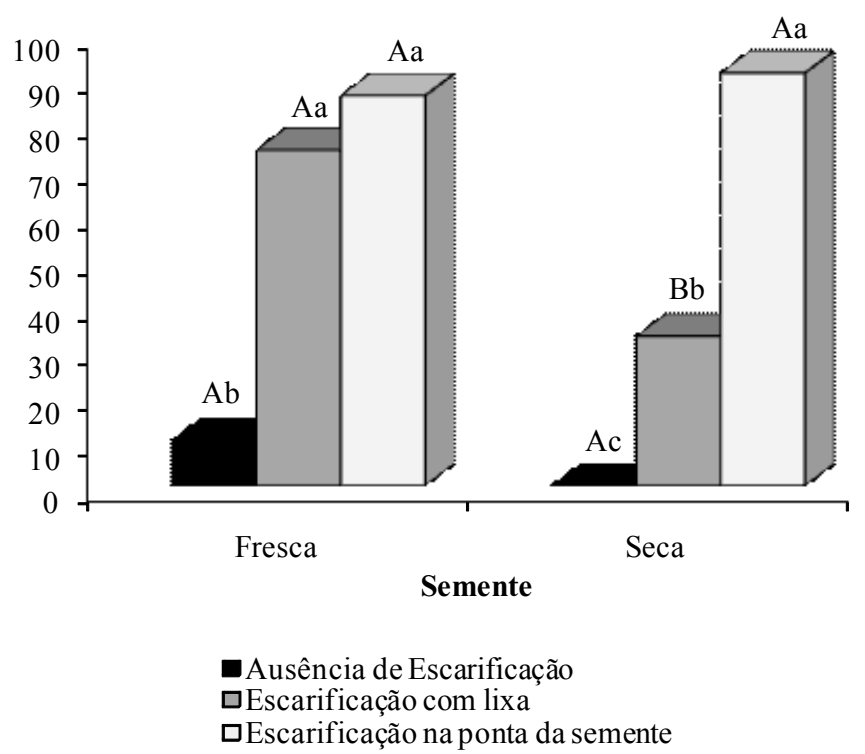

Fonte: Elaboração dos autores.

No presente trabalho, as sementes foram capazes de germinar independentemente da adição do regulador de crescimento $\mathrm{GA}_{3}$, não constituindo assim um caso de dormência embrionária. Esses resultados são contrários aos de autores que observaram incremento na germinação das sementes de várias espécies do gênero Passiflora quando da utilização de reguladores de crescimento (FERREIRA, 1998; ZONTA et al., 2005; FERRARI et al., 2008; FERRARI, 2009; LIMA et al., 2009; SANTOS et al., 2010; COSTA; SIMÕES; COSTA, 2010), inclusive a da espécie Passiflora gibertii (FERREIRA, 1998). Entretanto, a necessidade do rompimento do tegumento para ocorrência da germinação verificada no atual experimento, corrobora com trabalhos realizados com Passifloráceas (ZONTA et al., 2005; SANTOS et al., 2010).

Os resultados obtidos no presente trabalho estão de acordo com Junghans, Viana e Junghans (2006) que recomendam a retirada parcial do tegumento das sementes de Passiflora gibertii para a obtenção de plântulas in vitro. No entanto, os autores obtiveram, com o tratamento mecânico, $58 \%$ de germinação in vitro, e neste trabalho, o maior percentual de germinação obtido foi de $91 \%$. Provavelmente, os autores citados utilizaram métodos de escarificação que não expõem o embrião, como ocorre quando se retira a ponta do tegumento ou coletaram frutos em época diferente da utilizada no presente experimento. Outra possível explicação é a variação genética que pode haver entre acessos de uma mesma espécie, visto que se trata de uma planta nativa.

De maneira geral, as sementes frescas obtiveram maior percentagem de germinação $(56,67 \%)$ que as secas (41,33\%) (Figura 1). Correa et al. (2006), estudando o armazenamento de maracujazeiro doce (Passiflora alata Dryander), obtiveram resultados contrastantes, nos quais a percentagem de emergência de plântulas foi menor em sementes úmidas (frescas) do que aquelas que secaram à sombra por três dias.

O maior índice de velocidade de germinação (IVG) foi obtido para sementes frescas e secas 
com escarificação de suas pontas $(0,92$ e 0,88 , respectivamente) (Figura 2). Assim como os resultados obtidos para percentagem de germinação in vitro, a ausência de escarificação propiciou a velocidade mais lenta para sementes frescas $(0,03)$ e secas (0) (Figura 2), corroborando com os resultados anteriores.

Figura 2. Índice de velocidade de germinação (IVG) in vitro de sementes frescas e secas de Passiflora gibertii provenientes de diversos tipos de escarificação para superação de dormência.

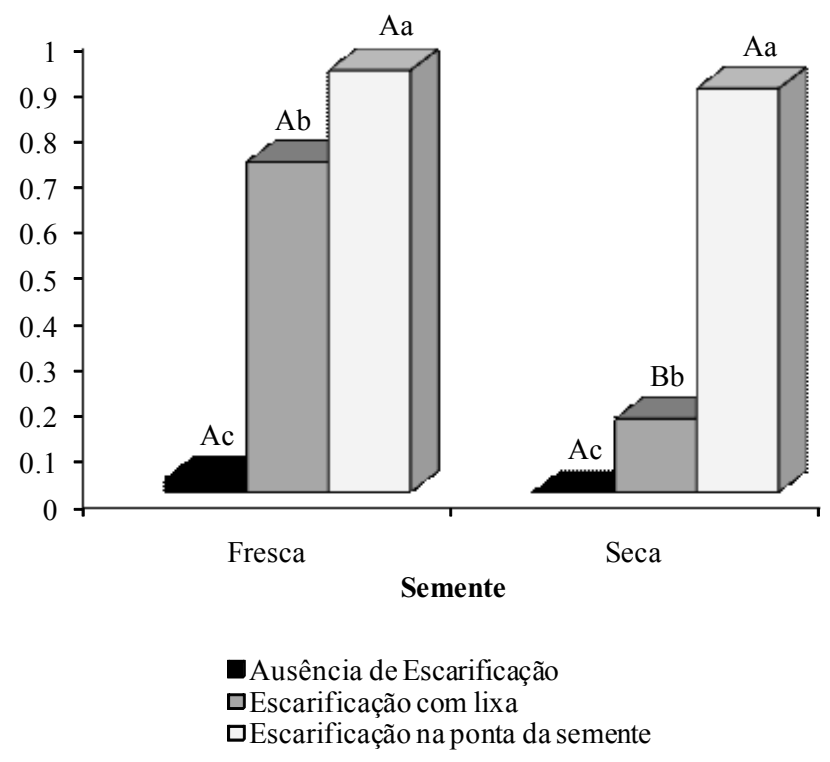

Fonte: Elaboração dos autores.

Em experimento realizado por Lima, Caldas e Santos (2006), o índice de velocidade de emergência (IVE) de Passiflora gibertii foi de 16,10 dias, sendo superior à espécie $P$. edulis f. flavicarpa $(8,85)$, que apresentou a maior velocidade de emergência. Confirmando os resultados obtidos no presente trabalho, a partir dos resultados de Lima, Caldas e Santos (2006), verifica-se que, para tornar a germinação de Passiflora gibertii economicamente viável, devem-se utilizar métodos de superação de dormência. A baixa germinação de espécies não domesticadas de maracujazeiro é bastante comum. A médio e longo prazos, o melhoramento genético vegetal deverá selecionar plantas dentro das populações, considerando a taxa de germinação das sementes, juntamente com outras características agronômicas. No entanto, até que se obtenha o valor expressivo de germinação, é necessário avaliar e desenvolver técnicas, daí a importância de realizarem-se pesquisas com estas espécies.

A escarificação da extremidade de sementes com pinça e bisturi proporciona maiores médias para a germinação e índice de velocidade de germinação de sementes de Passiflora gibertii. A adição do regulador de crescimento $\mathrm{GA}_{3}$ ao meio de cultura não afeta a germinação in vitro de Passiflora gibertii.

\section{Agradecimentos}

Este trabalho foi financiado pela Fundação de Amparo à Pesquisa do Estado de Minas Gerais (FAPEMIG), Coordenação de Aperfeiçoamento de Pessoal de Nível Superior (CAPES) e Conselho Nacional de Desenvolvimento Científico e Tecnológico (CNPq). 


\section{Referências}

BRAUN, H.; LOPES, J. C.; SOUZA, L. T.; SCHMILDT, E. R.; CAVATTE, R. P. Q.; CAVATTE, P. C. Germinação in vitro de sementes de beterraba tratadas com ácido giberélico em diferentes concentrações de sacarose no meio de cultura. Semina: Ciências Agrárias, Londrina, v. 31, n. 3, p. 539-546, jul./set. 2010.

CARDOSO, V. J. M. Germinação. In: KERBAUY, G. B. Fisiologia vegetal. Rio de Janeiro: Guanabara Koogan, 2004. $452 \mathrm{p}$.

CORREA, L. S.; ANSELMO, J. L.; BOLIANI, A. C.; SANTOS, P. C. Efeito do armazenamento de sementes sobre a emergência e desenvolvimento das plântulas de maracujazeiro doce. In: CONGRESSO BRASILEIRO DE FRUTICULTURA, 19., 2006, Cabo Frio, RJ. Anais... Cabo Frio: SBF/UENF/UFRuralRJ, 2006. p. 177.

COSTA, C. J.; SIMÕES, C. O.; COSTA, A. M. Escarificação mecânica e reguladores vegetais para superação de dormência de sementes de Passiflora setacea D. C. Planaltina: Embrapa Cerrados, 2010, 15 p. (Boletim de Pesquisa e Desenvolvimento, n. 271).

FERRARI, T. B. Metabolismo germinativo de sementes de Passiflora alata Curtis tratadas com giberelinas e citocinina. 2009. Tese (Doutorado em Ciências Biológicas) - Universidade Estadual Paulista. Instituto de Biociências, Botucatu.

FERRARI, T. B.; FERREIRA, G.; MISCHAN, M. M.; PINHO, S. Z. Germinação de sementes de maracujá-doce (Passiflora alata Curtis): fases e efeito de reguladores vegetais. Revista Biotemas, Florianópolis, v. 21, n. 3, p. 65-74, set. 2008.

FERREIRA, G. Estudo da embebição e efeito de fitorreguladores na germinação de sementes de Passifloráceas. 1998. Tese (Doutorado em Agronomia) - Universidade Estadual Paulista. Faculdade de Ciências Agronômicas. Botucatu.

JUNGHANS, T. G.; VIANA, A. J. C.; JUNGHANS, D. T. Germinação in vitro e ex vitro de sementes de maracujá gibertii com e sem tegumento parcialmente removido. In: CONGRESSO BRASILEIRO DE FRUTICULTURA, 19., 2006, Cabo Frio. Anais... Cabo Frio: SBF/UENF/ UFRuralRJ, 2006. p. 191.

JUNQUEIRA, N. T. V.; BRAGA, M. F.; FALEIRO, F. G.; PEIXOTO, J. R.; BERNACCI, L. C. Potencial de espécies silvestres de maracujazeiro como fonte de resistência a doenças. In: FALEIRO, F. G.; JUNQUEIRA, N. T. V.; BRAGA, M. F. Maracujá: germoplasma e melhoramento genético. Planaltina, DF: Embrapa Cerrados, 2005. p. 81106.

LIMA, A. A.; CALDAS, R. C.; SANTOS, V. S. Germinação e crescimento de espécies de maracujá. Revista Brasileira de Fruticultura, Jaboticabal, v. 28, n. 1, p. 125-127, abr. 2006.

LIMA, C. S. M.; BETEMPS, D. L.; TOMAZ, Z. F. P.; GALARÇA, S. P.; RUFATO, A. R. Germinação de sementes e crescimento de maracujá em diferentes concentrações do ácido giberélico, tempos de imersão e condições experimentais. Revista Brasileira de Agrociência, Pelotas, v. 15, n. 1-4, p. 43-48, jan./dez. 2009.

LIMA, E. C.; PAIVA, R.; NOGUEIRA, R. C.; SOARES, F. P.; EMRICH, E. B.; SILVA, A. A. N. Callus induction in leaf segments of Croton urucurana Baill. Ciência e Agrotecnologia, Lavras, v. 32, n. 1, p. 17-22, 2008.

MURASHIGE, T.; SKOOG, F. A revised medium for rapid growth and bioassays with tobacco tissue cultures. Physiologia Plantarum, Copenhagen, v. 15, n. 3, p. 473497, 1962.

RONCATTO, G.; LENZA, J. B.; VALENTE, J. P.; FERREIRA, L. G.; DAMASCENO, M. A. P. Avaliação da germinação de espécies nativas de maracujazeiro. In: CONGRESSO BRASILEIRO DE FRUTICULTURA, 19., 2006, Cabo Frio. Anais... Cabo Frio: SBF/UENF/ UFRuralRJ, 2006. p. 165.

SANTOS, F. C.; RAMOS, J. D.; PASQUAL, M.; REZENDE, J. C.; SANTOS, F. C.; VILLA, F. Micropropagação do maracujazeiro-do-sono. Revista Ceres, Viçosa, v. 57, n. 1, p. 112-117, jan./fev. 2010.

ZONTA, J. B.; SILVA, I. C.; DIAS, M. A.; CÔRREA, N. B.; LOPES, J. C. Germinação de sementes do maracujazeiro (Passiflora alata Dryand) submetidas a tratamentos físicos no tegumento e a pré-embebição em ácido giberélico $\left(\mathrm{GA}_{3}\right)$. In: ENCONTRO LATINOAMERICANO DE INICIAÇÃO CIENTÍFICA, 9; ENCONTRO LATINO-AMERICANO DE PÓS GRADUAÇÃO, 5., 2005, São José dos Campos. Anais... São José dos Campos, 2005. Disponível em: <http:// biblioteca.univap.br/dados/INIC/cd/inic/IC5\%20anais/ IC5-26.PDF. >. Acesso em: 27 nov. 2011. 